\title{
Micronutrients in COVID-19 Positive Pregnancies
}

Pinar Yalcin Bahat ${ }^{1}$, Merve Aldikactioglu Talmac ${ }^{1}$, Ayşegul Bestel ${ }^{1}$, Nura F. Topbas Selcuki ${ }^{2}$, Zelal Aydın ${ }^{1}$, İbrahim Polat ${ }^{1}$

1. Obstetrics and Gynaecology, Kanuni Sultan Süleyman Training and Research Hospital, University of Health Sciences, Istanbul, TUR 2. Obstetrics and Gynaecology, Health Sciences University, Istanbul Sisli Hamidiye Etfal Training and Research Hospital, Istanbul, TUR

Corresponding author: Pinar Yalcin Bahat, dr_pinaryalcin@hotmail.com

\begin{abstract}
Pregnant women are considered among the high-risk population for COVID-19. Therefore, research for methods of treatment and prevention of COVID-19 positive pregnancies carries an importance. The aim of this study was to measure serum $25(\mathrm{OH}) \mathrm{D}$, vitamin B12, and zinc levels in COVID-19 positive pregnant women to evaluate the role of these micronutrients in treatment and prevention. A total of 44 COVID-19 positive pregnant women who were hospitalized and treated at a tertiary clinic were included in this study. The mean serum $25(\mathrm{OH}) \mathrm{D}$ level was measured to be $9.70 \pm 59.14$. The mean serum zinc level was $62.58 \pm$ 2.63 , and the mean serum vitamin B12 level was $295.55 \pm 302.48$. All these variables were significantly lower than the accepted cut-off values $(\mathrm{p}<0.001)$. These low values might have contributed to a deficiency in their immune response and thus made these patients susceptible to COVID-19 infection. Supplementation of micronutrients during the pandemic could be beneficial during pregnancy for prevention.
\end{abstract}

Categories: Obstetrics/Gynecology, Public Health, Epidemiology/Public Health Keywords: 25 -oh vitamin d, zinc, covid-19 in pregnancy, micronutrients, serum vitamin b12

\section{Introduction}

Coronavirus family has long been a well-known source of infection causing diseases like common cold, severe acute respiratory syndrome (SARS), and Middle East respiratory syndrome (MERS). Novel coronavirus 2019 (SARS-CoV-2) is a newly discovered virus from the coronavirus family, which is the infection source of the COVID-19 pandemic [1]. COVID-19 enters the host cells and triggers an immune response, which includes the production of proinflammatory cytokines, activation of T cells, CD4, and CD8+ T cells [2]. The severe forms of the disease leading to acute respiratory distress syndrome have been attributed to excessive production of proinflammatory cytokines also called 'cytokine storm' [3]. Since the outbreak, extensive research has been put into understanding the action mechanism of COVID-19 in hope of finding a cure and a vaccine. However, there are still unknowns especially about the potential protective factors against the virus.

Received 08/05/2020 Review began 08/11/2020 Review ended 09/14/2020 Published 09/23/2020

() Copyright 2020

Yalcin Bahat et al. This is an open access article distributed under the terms of the Creative Commons Attribution License CC-BY 4.0., which permits unrestricted use, distribution, and reproduction in any medium, provided the original author and source are credited.
Vitamins and minerals, also known as micronutrients, are key factors in maintaining a healthy immune system and therefore are widely used as supplements for protection against bacterial and viral infections [4]. Zinc, 25 hydroxyvitamin D (25(OH)D), and vitamin B12 belong to this family of micronutrients.

Zinc is an essential micronutrient that is involved in cell proliferation, differentiation, RNA and DNA synthesis [5], as well as cell structures and cell membrane stabilization [6]. There is also strong evidence between zinc deficiency and several infectious diseases, such as malaria, HIV, tuberculosis, measles, and pneumonia. Zinc is also involved in the modulation of the proinflammatory response by regulation of inflammatory cytokines and in controlling oxidative stress [7]. Similarly, 25(OH)D has anti-infective, antiinflammatory, and immunomodulant functions. It contributes to the maintenance of the cell's physical barrier integrity, enhanced activity of innate immunity through macrophages and monocytes, and T cells [8]. Lastly, vitamin B12 is a water-soluble vitamin. It is a cofactor in DNA synthesis and is known to inhibit viral replication in the host cells [9].

The aim of this study was to measure serum 25(OH)D, vitamin B12, and zinc levels in COVID-19 positive pregnant women to evaluate the role of these micronutrients in the prevention and to evaluate the possible cause between the blood levels of micronutrients and the COVID-19 infection.

\section{Materials And Methods}

This case-control study was conducted in a tertiary referral hospital between April and June 2020. The study protocol was approved by the institution's Ethics Committee (2020.05.25) and registered to

ClinicalTrials.gov (NCT04407572). Written informed consent was obtained from all participants before their enrollment in the study.

\section{Study population}


A total of 44 COVID-19 positive pregnant women were included in the study. Pregnant women whose PCR test was positive for COVID-19, pregnancies older than eight weeks of gestation, and women who did not receive any antibacterial or antiviral treatment during the past three months or did not receive any $25(\mathrm{OH}) \mathrm{D}$, vitamin B12, and zinc supplements during their pregnancy were included in the study. Women with known renal disease, rheumatic disease, diabetes mellitus type 1, acquired immune deficiency syndrome, and those using immunosuppressants were excluded. Complicated pregnancies such as ectopic pregnancy, scar pregnancy, or hydatidiform mole were also excluded.

A detailed medical history was obtained. All patients underwent a physical and obstetrical examination with ultrasound and received a thorax CT. In addition to routine blood tests, D-dimer levels and ferritin levels were also determined. Gestational age was estimated based on the last menstrual period. If the date of the last menstruation was unknown, then crown-rump length (CRL) was used for calculation.

\section{Laboratory analysis}

On the day of admission, blood samples were taken from a peripheral vein using one dry tube and one tube with ethylenediaminetetraacetic acid (EDTA). Tubes were submitted to the hospital's central laboratory for determination of 25(OH)D, zinc, and vitamin B12 levels. Quantitative determination of 25(OH)D was performed with competitive chemiluminescent immunoassay (CLIA) using LIAISON ${ }^{\circledR} 25$ OH Vitamin D TOTAL Assay (DiaSorin S. p. A., Saluggia, Italy). Vitamin D deficiency was defined as serum vitamin D levels of less than $20 \mathrm{ng} / \mathrm{mL}$, insufficiency as $21-29 \mathrm{ng} / \mathrm{mL}$, and sufficiency as 30-100 ng/mL according to recent Clinical Guidelines Committee. Recommended levels are higher than $30 \mathrm{ng} / \mathrm{mL}$ for specific groups, such as in pregnant women. The mean of $19.9 \mathrm{ng} / \mathrm{mL}$ (SD: $0.948 \mathrm{ng} / \mathrm{mL}$ and an intra-control CV of $4.8 \%$ ) was the referred reproducible value to measure the 25(OH)D. For the same parameter, the intermediate precision was $19.9 \mathrm{ng} / \mathrm{mL}$ (SD: $1.23 \mathrm{ng} / \mathrm{mL}$ and an intra-control CV of 6.2\%) [10]. Access Immunoassay System (C) 2020Beckman Coulter Inc., Brea, CA, USA) was used to quantitate serum vitamin B12 levels. A normal range of 100-350 pmol/L serum vitamin B12 was calculated with a 95\% confidence interval [11]. For zinc quantification, atomic absorption spectroscopy was used (PerkinElmer ${ }^{\circledR}$ Inc., Waltham, MA, USA). Current cut-off levels for zinc deficiency are $<8.7 \mu \mathrm{mol} / \mathrm{L}$ (afternoon, non-fasting) and for non-fasting women of reproductive age (aged 18-49 years; WRA, <10.1 $\mu \mathrm{mol} / \mathrm{L}$ (morning) and $<9.0 \mu \mathrm{mol} / \mathrm{L}$ (afternoon)) [12]. All calculations followed the best clinical practice.

\section{Statistical analysis}

Statistical Package for Social Sciences 23.0 (IBM Corp., Armonk, NY, USA) was used for statistical analysis. Descriptive statistical methods (mean, standard deviation, frequency) and their associated 95\% confidence intervals of study variables were presented. One sample t-test was performed to evaluate the difference between accepted cut-off values and the means of our study groups regarding B12, zinc, and 25(OH)D levels. $\mathrm{P}$-value $<0.05$ was considered for statistical significance.

\section{Results}

A total of 44 COVID-19 positive pregnant women were included in the study. The mean age was $28.57 \pm 7.77$ years. When pregnancies were divided into trimesters, it was observed that disease rate in our cohort increased with increasing trimester: $8.8 \%(n=5)$ was in the first trimester, $27.2 \%(n=12)$ were in the second trimester, and $61.3 \%(n=27)$ were in the third trimester. The mean gravidity was $2.75 \pm 1.74$, and the mean parity was $1.32 \pm 1.37$ (Table 1 ). 


\section{Cureus}

\begin{tabular}{|c|c|c|c|c|}
\hline \multicolumn{2}{|l|}{ Demographic characteristics } & Mean and standard deviation, n (\%) & $95 \% \mathrm{Cl}$ lower & 95\% Cl upper \\
\hline \multicolumn{2}{|l|}{ Age (years) } & $28.57 \pm 7.77$ & 26.45 & 30.80 \\
\hline \multicolumn{2}{|l|}{ Gravida (n) } & $2.75 \pm 1.74$ & 2.27 & 3.30 \\
\hline \multicolumn{2}{|l|}{ Parity (n) } & $1.32 \pm 1.37$ & 0.93 & 1.73 \\
\hline \multicolumn{2}{|l|}{ Zinc $(70-114 \mu \mathrm{mol} / \mathrm{L})$} & $62.58 \pm 2.63$ & 54.81 & 70.18 \\
\hline \multicolumn{2}{|l|}{ Vitamin D (20-80 ng/mL) } & $9.70 \pm 59.14$ & 8.06 & 11.54 \\
\hline \multicolumn{2}{|l|}{ Vitamin B12 (197-771 pmol/L) } & $295.55 \pm 302.48$ & 2.21 & 3.93 \\
\hline \multirow{3}{*}{ Trimester } & 1 & $5(11.4 \%)$ & 2.3 & 22.7 \\
\hline & 2 & $12(27.3 \%)$ & 13.6 & 40.9 \\
\hline & 3 & $27(61.4 \%)$ & 47.7 & 75.0 \\
\hline \multirow{4}{*}{ CT } & 0 & $17(38.63 \%)$ & 25.0 & 54.5 \\
\hline & 1 & $12(27.27 \%)$ & 13.6 & 40.9 \\
\hline & 2 & $12(27.27 \%)$ & 15.9 & 40.9 \\
\hline & 3 & $3(6.81 \%)$ & 0.0 & 13.6 \\
\hline \multirow{2}{*}{ Hydroxychloroquine treatment } & Yes & $18(40.90 \%)$ & 27.3 & 56.8 \\
\hline & No & $26(59.10 \%)$ & 43.2 & 72.2 \\
\hline D-Dimer levels (ng/mL) & & $1.72 \pm 0.91$ & 1.47 & 2.00 \\
\hline Ferritin levels (ng/mL) & & $64.10 \pm 187.62$ & 3.15 & 12.42 \\
\hline Duration of hospital stay (days) & & $6.63 \pm 1.70$ & - & - \\
\hline
\end{tabular}

\section{TABLE 1: Patient's demographic data}

When thorax CTs were evaluated, 38.63\% ( $\mathrm{n}=17$ ) did not reveal any pathology, 27.327\% ( $\mathrm{n}=12)$ showed mild changes, and in $27.27 \%(\mathrm{n}=12)$ moderate and in $6.81 \%(\mathrm{n}=3)$ severe findings could be observed. Majority of the patients in the study presented with mild to moderate CT findings. Approximately $40.90 \%$ were treated with hydroxychloroquine, whereas $59.10 \%$ were monitored actively without any medical intervention. At the time of admission, the mean serum D-dimer level was $1.72 \pm 0.91$ and the ferritin level was $64.10 \pm 187.62$. The mean duration of stay at the hospital was $6.63 \pm 1.70$ (3-11) (Table 1). While the minimum stay in the hospital was 3 days and the maximum stay was 11 days.

The mean serum 25(OH)D level was measured to be $9.70 \pm 59.14$. The mean serum zinc level was $62.58 \pm$ 2.63 , and the mean serum vitamin B12 level was $295.55 \pm 302.48$ (Table 1). In one sample t-test analysis, all these variables were significantly lower than the accepted cut-off values (p-value $<0.001$ ): $25(\mathrm{OH}) \mathrm{D}: 30$, zinc: 10.1, and B12: 100.

\section{Discussion}

Understanding the pathogenesis of SARS-CoV-2 has been challenging, and it has not yet been clarified. However, COVID-19 affects the immune system in many different steps in the disease process [13]. Micronutrients are among these immune supplements, and their efficacy has already been shown with other viral infections [14].

Previous studies conducted with pregnant women and women in the postpartum period have shown the efficacy of micronutrients in fight against viral infections. Especially, the inhibitory effects of 25(OH)D, vitamin B12, and zinc, due to their safe use during pregnancy, on viral pathogenesis have already been shown. For example, in studies of H1N1 prior to the finding of a vaccine, the protective effects of high levels of vitamin B12 on the newborns ingested through breast milk were observed [15]. Another study has shown that high levels of maternal serum $25(\mathrm{OH}) \mathrm{D}$ levels during pregnancy and lactation were associated with lower rates of acute respiratory infections of the newborns [16]. Additionally, it has been shown that serum zinc levels correlate positively with better immune response in pregnant women against infections [17]. 
It is known that 25(OH)D plays an essential role in immune answer and its modulation [18,19]. In a study conducted by Ilie et al., in countries that had a severe course of COVID-19 such as Spain, Italy, and the United Kingdom, mean serum 25(OH)D levels are low [20]. Another study showed that patients with high serum vitamin D levels sustained less lung damage. According to a study by Alipio, lower rates of multiple organ failure were observed among patients with higher levels of serum 25(OH)D [21]. From the existing evidence, it can be concluded that the suppression of viral replication by $25(\mathrm{OH}) \mathrm{D}$ is effective in the prevention and also responsible for a mild course of COVID-19 [22]. In our study, serum 25(OH)D levels of the COVID-19 positive pregnant women were under the cutoff value. The reason for these low values could be pregnancy, less exposure to sunlight, and insufficient nutrition. The low levels of serum 25(OH)D, in accordance with the existing data, might have caused susceptibility to COVID-19.

Zinc plays an important role in the pathogenesis of viral infections. The correlation between serum zinc levels and the severity of infections has already been shown [7]. Anosmia, a common symptom of COVID-19, is also seen in zinc deficiency [23]. In three women, included in the study, with very low levels of serum zinc, anosmia was among the symptoms. Shittu and Afolami advocated in their study that adding zinc supplements to the treatment regimen with chloroquine in COVID-19 patients enhanced the antiviral action mechanism of the chloroquine and efficacy of the treatment [24]. According to another study, it has been suggested that zinc could possess protective effects through reducing inflammation, improving mucociliary clearance, preventing ventilator-induced lung injury, and modulating antiviral and antibacterial immunity [25]. Therefore, zinc can be used both as preventative medication and adjuvant therapy of COVID-19. Similar to the results with 25(OH)D, zinc levels were significantly low in our patient cohort, which might have played a negative effect on their immunity making these patients susceptible during the pandemic.

In vivo studies of vitamin B12 have shown that vitamin B12 acts as a natural inhibitor of viral replication of the hepatitis C virus (HCV) [26]. In another study, it was shown that vitamin B12 and folate levels affect the human papillomavirus methylation process and low serum levels increase malignancy [27]. In our study, all serum vitamin B12 levels were significantly low can be making them more prone to COVID-19.

There are several limitations to this study. First, there are difficulties in the measurement of serum 25(OH)D levels in pregnant women, which might have led to the lower levels observed in this study. Additionally, a limited number of patients and a lack of a control group were further limitations. However, due to the need for cumulative data concerning the COVID-19 pandemic, we believe that our results will be of importance for further studies on prevention and adjuvant therapy.

\section{Conclusions}

The level of serum micronutrients in pregnant women with COVID-19 was lower than the cut-off values. These low values might have contributed to a deficiency in their immune response and thus made these patients susceptible to COVID-19 infection. Supplementation of micronutrients during the pandemic could be beneficial during pregnancy for prevention. However, further studies are needed to show their effects on COVID-19 infection.

\section{Additional Information \\ Disclosures}

Human subjects: Consent was obtained by all participants in this study. Kanuni Sultan Suleyman Hospital issued approval KAEK/2020.05.25. registered to ClinicalTrials.gov (NCT04407572). . Animal subjects: All authors have confirmed that this study did not involve animal subjects or tissue. Conflicts of interest: In compliance with the ICMJE uniform disclosure form, all authors declare the following: Payment/services info: All authors have declared that no financial support was received from any organization for the submitted work. Financial relationships: All authors have declared that they have no financial relationships at present or within the previous three years with any organizations that might have an interest in the submitted work. Other relationships: All authors have declared that there are no other relationships or activities that could appear to have influenced the submitted work.

\section{Acknowledgements}

The authors would like to thank Assistant Professor Cihan Kaya for his support and advice.

\section{References}

1. Li H, Liu SM, Yu XH, Tang SL, Tang CK: Coronavirus disease 2019 (COVID- 19): current status and future perspectives. Int J Antimicrob Agents. 2020, 55:105951. 10.1016/j.ijantimicag.2020.105951

2. Tufan A, Avanoğlu Güler A, Matucci-Cerinic M: COVID-19, immune system response, hyperinflammation and repurposing antirheumatic drugs. Turk J Med Sci. 2020, 50:620-632. 10.3906/sag-2004-168

3. Ye Q, Wang B, Mao J: The pathogenesis and treatment of the 'Cytokine Storm' in COVID-19 . J Infect. 2020, 80:607-613. 10.1016/j.jinf.2020.03.037

4. Jayawardena R, Sooriyaarachchi P, Chourdakis M, Jeewandara C, Ranasinghe P: Enhancing immunity in viral infections, with special emphasis on COVID- 19: a review. Diabetes Metab Syndr. 2020, 14:367-382. 
10.1016/j.dsx.2020.04.015

5. Rink L, Gabriel P: Zinc and the immune system. Proc Nutr Soc. 2000, 59:541-552.

$10.1017 /$ s0029665100000781

6. Maret W, Li Y: Coordination dynamics of zinc in proteins. Chem Rev. 2009, 109:4682-4707. 10.1021/cr800556u

7. Maret W: Zinc and human disease. Interrelations between Essential Metal Ions and Human Diseases. Sigel A, Sigel H, Sigel RK (ed): Springer, Dordrecht, The Netherlands; 2013. 13:389-414.

8. Zhang Y, Fang F, Tang J, Jia L, Feng Y, Xu P, Faramand A: Association between vitamin D supplementation and mortality: systematic review and meta-analysis. BMJ. 2019, 366:14673. 10.1136/bmj.14673

9. Mechie NC, Goralzcyk AD, Reinhardt L, Mihm S, Amanzada A: Association of serum vitamin B 12 levels with stage of liver fibrosis and treatment outcome in patients with chronic hepatitis $C$ virus genotype 1 infection: a retrospective study. BMC Res Notes. 2015, 8:260. 10.1186/s13104-015-1248-z

10. Thacher TD, Clarke BL: Vitamin D insufficiency. Mayo Clin Proc. 2011, 86:50-60. 10.4065/mcp.2010.0567

11. Aparicio-Ugarriza R, Palacios G, Alder M, González-Gross M: A review of the cut-off points for the diagnosis of vitamin B12 deficiency in the general population. Clin Chem Lab Med. 2015, 53:1149-1159. 10.1515/cclm2014-0784

12. Wieringa FT, Dijkhuizen MA, Fiorentino M, Laillou A, Berger J: Determination of zinc status in humans: which indicator should we use?. Nutrients. 2015, 7:3252-3263. 10.3390/nu7053252

13. Li G, Fan Y, Lai Y, et al.: Coronavirus infections and immune responses. J Med Virol. 2020, 92:424-432. $10.1002 / j m v .25685$

14. Calder PC, Carr AC, Gombart AF, Eggersdorfer M: Optimal nutritional status for a well-functioning immune system is an important factor to protect against viral infections. Nutrients. 2020, 12:1181. 10.3390/nu12041181

15. Siddiqua TJ, Ahmad SM, Ahsan KB, et al.: Vitamin B12 supplementation during pregnancy and postpartum improves B12 status of both mothers and infants but vaccine response in mothers only: a randomized clinical trial in Bangladesh. Eur J Nutr. 2016, 55:281-293. 10.1007/s00394-015-0845-X

16. Morris SK, Pell LG, Rahman MZ, et al.: Maternal vitamin D supplementation during pregnancy and lactation to prevent acute respiratory infections in infancy in Dhaka, Bangladesh (MDARI trial): protocol for a prospective cohort study nested within a randomized controlled trial. BMC Pregnancy Childbirth. 2016, 16:309. 10.1186/s12884-016-1103-9

17. Vygivska LA: Peculiarities of changes in indices of calcium and zinc trace elements and matrix metalloproteinase-2 in pregnant women with perinatal infections. Wiad Lek. 2019, 72:2076-2081.

18. Jakovac H: COVID-19 and vitamin D-Is there a link and an opportunity for intervention? . Am J Physiol Endocrinol Metab. 2020, 318:E589. 10.1152/ajpendo.00138.2020

19. Pérez-López FR, Fernández-Alonso AM, Chedraui P, Moreno LA; Spanish Vitamin D and Women's Health Research Group: Hypovitaminosis D during pregnancy: are we ready to recommend vitamin D supplementation?. Gynecol Endocrinol. 2012, 28:856-858. 10.3109/09513590.2012.671392

20. Ilie PC, Stefanescu S, Smith L: The role of vitamin D in the prevention of coronavirus disease 2019 infection and mortality. Aging Clin Exp Res. 2020, 32:1195-1198. 10.1007/s40520-020-01570-8

21. Alipio M: Vitamin D supplementation could possibly improve clinical outcomes of patients infected with coronavirus-2019 (COVID-19) [Epub ahead of print]. SSRN Electronic J. 2020,

22. McCartney DM, Byrne DG: Optimisation of vitamin D status for enhanced immuno-protection against Covid-19. Ir Med J. 2020, 113:58.

23. Welge-Lüssen A: Re-establishment of olfactory and taste functions. GMS Curr Top Otorhinolaryngol Head Neck Surg. 2005, 4:Doc06.

24. Shittu MO, Afolami OI: Improving the efficacy of chloroquine and hydroxychloroquine against SARS-CoV-2 may require zinc additives-a better synergy for future COVID-19 clinical trials. Infez Med. 2020, 28:192197.

25. Skalny AV, Rink L, Ajsuvakova OP, et al.: Zinc and respiratory tract infections: perspectives for COVID-19 . Int J Mol Med. 2020, 46:17-26. 10.3892/ijmm.2020.4575

26. Rocco A, Compare D, Coccoli P, et al.: Vitamin B12 supplementation improves rates of sustained viral response in patients chronically infected with hepatitis C virus. Gut. 2013, 62:766-773. 10.1136/gutjnl2012-302344

27. Piyathilake CJ, Macaluso M, Chambers MM, et al.: Folate and vitamin B12 may play a critical role in lowering the HPV 16 methylation-associated risk of developing higher grades of CIN. Cancer Prev Res (Phila). 2014, 7:1128-1137. 10.1158/1940-6207.CAPR-14-0143 